\title{
Topics in Catalysis: The Gabor and Judith Somorjai Award for Creativity in Catalysis to Mark Davis, 2014
}

\author{
Stacey I. Zones ${ }^{1}$
}

Published online: 31 March 2015

(c) Springer Science+Business Media New York 2015

In 2014, Professor Mark Davis was honored with the Gabor and Judith Somorjai Award for Creativity in Catalysis. I was asked to organize a Symposium for the 247th ACS meeting (Dallas, 2014) in honor of Professor Davis. Typically such symposia include an array of key researchers in the area. But what made this symposium so unusual is that, with only a few exceptions, the contributors were all scientists who had worked in the Davis Lab earlier in their careers. It became a wonderful opportunity for these researchers to honor an important mentor in their development as scientists.

Papers were presented by 18 former lab members, and from longtime Davis Group collaborators, Professors Michael Deem and Osamu Terasaki. While much of the work that had been done in the Davis group centered on zeolites, there was an array of scientific themes, showcasing current work by former group members. This variety is reflected in the papers assembled here. Professor Somorjai decided that the Symposium had been such a successful event that we should try to capture it in print. And so we come forward with this special issue.

It was particularly fitting for Professor Davis to be honored with an Award in Creativity in Catalysis as his career has been characterized by sudden changes in direction and breakthroughs. In the past several years there have been several wonderful discoveries in his lab spanning the creation of new catalysts, creation of new reactions of interest and utility using catalysis, and greater insight into reaction mechanisms in catalysis for some of

Stacey I. Zones

sizo@chevron.com

1 Chevron Research and Technology Company, Richmond, CA 94802, USA this novel chemistry. Roman-Leshkov and Moliner from the current Davis group studied control of the location of acid sites in dual channel zeolites by choosing a combination of more than one guest molecule to fill the pore systems [1]. The materials have become of considerable interest since the discovery of their unique utility in carbonylation reactions. The group also examined the details of a surprising reaction in biomass conversion: the use of Sn Beta zeolite to perform isomerisation of sugars, even in water [2]. The synthesis work demonstrated the importance of carefully controlled procedures to ensure that the Sn atoms locate in the framework of the zeolite and not on the outside. The Davis group was the first to introduce isotopically enriched Sn MASNMR into the analysis [3]. Recently, another student demonstrated novel Diels-Alder chemistry for such a catalyst, emphasizing the role of Lewis Acidity as key in these reactions [4]. Importantly, the focus of the chemistry was on biomass molecular conversions into useful industrial chemicals. Professor Davis's research student Bhawe provided an important study [5] contrasting cage space and lattice acid content in evaluating a series of ABC- 6 family zeolites for the MTO reaction; the CHA material is the structure with industrial use. This technology is now seeing a renewal of interest as processes are underway to start with coal and deliver high yields of ethylene and propylene through the sequence of syngas and MTO reactions. The theme here is that the Davis group both finds new catalytic reactions and analyzes the commercial value of such reactions. You will read about some of this work in this issue.

The proliferation of great work from the Davis Group, is representative of his breadth of interests, and his ability and drive in bringing together fundamental studies done with great care pointed at problems where the outcomes have technological and commercial relevance. I believe this has 
been part of the great training imparted to the generations of researchers who have passed through his lab. In the Symposium we had a chance to hear, aside from the exciting work currently being carried out by former lab members, their deeply sincere appreciation of what they had learned from Mark and how they had benefitted from their time in the group. I hope that this gratitude comes across in these papers.

\section{References}

1. Roman-Leshkov Y, Moliner M, Davis ME (2011) Impact of controlling the site distribution of $\mathrm{Al}$ atoms on catalytic properties in ferrierite-type zeolites. J Phys Chem C 115:1096
2. Moliner M, Roman-Leshkov Y, Davis ME (2010) Tin-containing zeolites are highly active catalysts or the isomerization of glucose in water. Proc Natl Acad Sci USA 107:6164

3. Bermejo-Deval R, Assary RS, Nikolla E, Moliner M, RomanLeshkov Y, Hwang SJ, Palsdottir A, Silverman D, Lobo R, Curtiss LA, Davis ME (2012) Metalloenzyme-like catalyzed isomerizations of sugars by Lewis acid zeolites. Proc Natl Acad Sci USA 109:9727

4. Pacheco JJ, Davis ME (2014) Synthesis of terephthalic acid via Dies-Alder reactions with ethylene and oxidized variants of 5-hydroxymethylfurfural. Proc Natl Acad Sci USA 111:8363

5. Bhawe Y, Moliner-Marin M, Lunn JD, Liu Y, Malek A, Davis ME (2012) Effects of cage size on the selective conversion of methanol to light olefins. ACS Catal 2:2490 